\title{
Occurrence of Shiga toxin producing $E$. coli from raw milk
}

\author{
Abdul Razzaq ${ }^{1 *}$, Sadia Shamsi ${ }^{2}$, Aisha $\mathrm{Nawaz}^{3}$, Aisha Nawaz ${ }^{3}$, Arfan \\ Ali $^{1}$ and K. A. Malik ${ }^{4}$ \\ 1. Institute of molecular biology and biotechnology, The University of Lahore-Pakistan \\ 2. Department of Pharmacy, The University of Lahore-Pakistan \\ 3. Lahore College for women, Lahore-Pakistan \\ 4. Biological sciences department, Forman Christian College, Chartered University, Lahore-Pakistan \\ *Corresponding author's email: biolformanite@gmail.com
}

Citation

Abdul Razzaq, Sadia Shamsi, Aisha Nawaz, Aisha Nawaz, Arfan Ali and K. A. Malik. Occurrence of Shiga toxin producing E. coli from raw milk. Pure and Applied Biology. Vol. 5, Issue 2, 2016, pp270-276.

http://dx.doi.org/10.19045/bspab.2016.50035

\begin{tabular}{llll}
\hline \hline Received: 28/12/2015 & Revised: 11/02/2016 & Accepted: 18/02/2016 & Online First: 04/03/2016 \\
\hline
\end{tabular}

\section{Abstract}

Shiga toxin producing E. coli (STEC) causes GIT illnesses in human originating in food of animals all over the world. The aim of this study was to make rapid diagnostics of Shiga toxin producing E. coli (STEC) from raw milk. During a 4 month period from May to August a total of 100 samples were collected milk (100) and analyzed for Shiga toxin producing E. coli. of the total of 100 samples of raw milk only milk (1\%) were detected as PCR positive. Raw milk could be a source of Shiga toxin producing $E$. coli which indicates that possible risks of infections to people could be transferred by the consumption of raw milk and their rapid diagnostics could be made possible by the use of rapid diagnostic technique polymerase chain reaction.

Key words: STEC; Stx; Raw milk Stx; Foodborne pathogens

\section{Introduction}

In the intestinal micro flora of humans and mammals Escherichia coli (E. coli) are predominantly found. A German pediatrician 'Theodor Escherich in 1885 discovered E. coli belonging to a family Enterobacteriaceae and this bacterium is one of the inhabitants of intestine. These commensals never cause a problem in their host but some pathogenic E. coli are involved in diarrhea and other enteric illnesses and are called diarrheagenic E. coli. It harmlessly colonizes the intestine but several strains of $E$. coli cause various intestinal diseases. E. coli are described as Gram negative, facultative anaerobe, nonspore forming; rod shaped and is generally motile. [1]. It has been divided into six pathotypes that includes atypical enteropathogenic $E$. coli (ATEC), enteropathogenic $E$. coli (EPEC), enteroaggregative $E$. coli (EAEC), enterotoxigenic $E$. coli (ETEC), enterohemorrhagic or Shiga toxin producing E. coli (EHEC/STEC) and enteroinvasive $E$. coli (EIEC) [2]. These pathotypes indicate the plasticity of $E$. coli genome and the genome of STEC O157:H7 contains 5416 genes in $5.5 \times 10^{6}$ base pairs of DNA [3] which is considered the most prominent and notorious STEC and its incidence varies according to age group and in most of the cases the etiological agent is food stuff [4]. 
Shiga toxin producing E. coli (STEC) is responsible for causing an increasing number of human outbreaks, characterized by bloody diarrhea, non-bloody diarrhea, hemorrhagic colitis and hemolytic uremic syndrome (HUS) and $85 \%$ of these cases are implicated with foodborne transmission. stx is further subdivided into two families' stx 1 and stx 2 on the basis of sequence analysis. The cardinal virulent factors, of STEC are stxl and stx 2 and are referred as cytotoxic $[2,5]$.

The association of STEC outbreaks has been considered with a variety of dairy products especially raw meat and milk if they are not properly cooked or boiled [6]. A number of reports have been submitted on the sources of transmitting the STEC such as water [7], yogurt [8] and airborne [9] as well. Human outbreaks of STEC are more derived from ground beef than any other source [6]. In particular, ruminants and cattle are considered the primary source of E. coli O157:H7 [10, 11]. It was also reported that person to person contact is also a source for the transformation of STEC and it was also manifested that STEC is shed by the infected person through stool even after a month of recovery [12].

In New Hampshire and Vermont associated with a particular restaurant in eastern Vermont an outbreak of STEC has been detected while the source of outbreak has not been identified. Although one confirmed and two probable cases associated with the outbreak were reported in New Hampshire during a period from August 27, 2015 to September 26, 2015, with illness onset from September 5, 2015 to October 1, 2015 (13). Due to number of constraints, the conventional approaches for detection of foodborne pathogens were replaced by polymerase chain reaction in advanced countries. In Pakistan, however, the PCR has not been currently evaluated for its efficacy for the detection of foodborne pathogens from beef, mutton, chicken and milk due to the paucity of information on the PCR based detection of foodborne pathogens. The conventional approaches to detect food related bacteria rely on the selective enrichment and culture characteristics followed by biochemical characterization. These methods are time consuming, labor intensive and often not reliable in contrast to PCR which is a rapid molecular test with high sensitivity and specificity

\section{Material and method}

A total of 100 samples of raw milk were collected in PBS from various regions of Lahore and were carried to the laboratory under refrigerated conditions. After the enrichment of these samples in tryptic soya broth, were streaked on MacConkey agar for the identification of E. coli and then on Sorbitol MacConkey agar for the differentiation of pathogenic and nonpathogenic $E$. coli after overnight incubation at $37^{\circ} \mathrm{C}$ aerobically. The confirmation of $E$. coli was done by conducting two biochemical tests, the catalase test using a drop of 3\% hydrogen peroxide and gently mixed with the colonies of $E$. coli isolated of plates and a triple sugar iron test by preparing a butt to the $3 / 4^{\text {th }}$ portion of the test tube and then gently pulled back the loop and streaked on the slant area without lifting up the loop. The tubes were plugged properly with cotton plug and incubated at $37^{\circ} \mathrm{C}$ for overnight aerobically.

Finally, the detection of STEC (Stxl and Stx2) was confirmed by employing a molecular approach polymerase Chain Reaction which proved to be a rapid and reliable method for the detection of foodborne bacterial pathogens. For the detection of Shiga toxin1 (stxl) and Shiga toxin2 (stx2) on all the isolates of E. coli from the samples of raw meat and milk, a molecular approach was conducted i.e. polymerase chain reaction (PCR). This 
molecular approach was designed for the detection of virulence genes of $E$. coli isolates. Primers with unique sequences were used for the detection of the targeted genes and a primer sequence is available in tabular form in (Table 1). All PCR reagents were supplied by Thermo scientific USA and all PCR assays were performed in PCR Master Cycler (Eppendorfs Germany).

Table 1. PCR primers used in this study

\begin{tabular}{|l|l|l|l|}
\hline $\begin{array}{l}\text { Target } \\
\text { gene }\end{array}$ & $\begin{array}{l}\text { Primer } \\
\text { name }\end{array}$ & \multicolumn{1}{|c|}{ Sequence 5-3 } & Amplicon size \\
\hline Stx1 & $\begin{array}{l}\text { KS7 (F) } \\
\text { KS8 (R) }\end{array}$ & $\begin{array}{l}\text { CCCGGATCCATGAAAAAAACATTATTAATAGC } \\
\text { CCCAATTCAGCTATTCTGAGTCAACG }\end{array}$ & $\mathbf{2 8 2 b p}$ \\
\hline Stx 2 & $\begin{array}{l}\text { LP43(F) } \\
\text { LP44(R) }\end{array}$ & $\begin{array}{l}\text { ATCCTATTCCCGGGAGTTTACG } \\
\text { GCGTCATCGTATACACAGGAGC }\end{array}$ & $\mathbf{5 8 4 b p}$ \\
\hline
\end{tabular}

KS7 and KS8 primers were used for the identification of stxl gene. Final mixture of PCR reaction was $25 \mu \mathrm{l}$ with $2.0 \mu \mathrm{l}$ bacterial cells as template, $15.3 \mu \mathrm{l}$ autoclaved water, $2.5 \mu \mathrm{l}$ of 10X Taq buffer, $\mathrm{MgCl} 21.5 \mu \mathrm{l}, 0.5$ $\mu \mathrm{l}$ of dNTPs ( $5 \mathrm{mM}$ each of dATP, dCTP, dGTP, dTTP), $1.5 \mu$ each of forward and reverse primer $(20 \mathrm{pmol})$ and $0.2 \mu \mathrm{l}$ of DNA Taq polymerase $(5.0 \mathrm{U} / \mu \mathrm{l})$. Thermal cycler conditions used for Stxl were, Initial denaturation was adjusted at $95^{\circ} \mathrm{C}$ for 10 min. stxl gene was amplified for 30 cycles, each cycle with 30 seconds of denaturation at $94^{\circ} \mathrm{C}, 1 \mathrm{~min}$ for primer annealing at $52^{\circ} \mathrm{C}$ and $1 \mathrm{~min}$ for extension at $72^{\circ} \mathrm{C}$ followed by final extension at $72^{\circ} \mathrm{C}$ for $5 \mathrm{~min}$ and for Stx 2 using primers LP43 and LP44, After initial denaturation at $95^{\circ} \mathrm{C}$ for 10 minutes amplification of DNA product for each cycle were for repeated 30 cycles with denaturation at $94^{\circ} \mathrm{C}$ for 30 seconds, primer annealing at $57^{\circ} \mathrm{C}$ for 1 minute, extension at $72^{\circ} \mathrm{C}$ for 1.5 minutes followed by final extension at $72^{\circ} \mathrm{C}$ for 5 minutes.

\section{Results}

Of the total 100 samples of raw milk cultured on MacConkey agar showed 57 lactose fermenting pink colonies of $E$. coli. These colonies were then incorporated for further confirmation of $E$. coli using biochemical tests.

Triple sugar iron test (TSI) was performed on these pink colonies of $E$. coli for the confirmation of $E$. coli in which yellow color of the medium in all test tubes was observed which indicated the fermentation of all three sugars such as sucrose, lactose and glucose that leaded to the determination of E. coli. In addition to TSI, another biochemical test, catalase test was conducted on the same number of pink colonies for the confirmation of $E$. coli and a moderate reaction was observed with precipitation or bubbling which indicated the presence of $E$. coli. After these biochemical confirmations these rose pink colonies of $E$.coli were further preceded for the determination of STEC using molecular methods. All plates with pink colonies of milk (57\%) were streaked on SMAC. SMAC displayed Sorbitol fermenting (SF) rose pink colonies 28 and non-Sorbitol fermenting (NSF) colorless colonies 29 (Table 2). These NSF colonies of milk were detected as PCR positive with $1 \%$ of milk, harboring STEC genes either stx 1 or stx 2 while none of the SF colonies were detected as PCR positive (Figure 1). 
Table 2. Isolation frequency of $E$. coli (STEC) from various sources

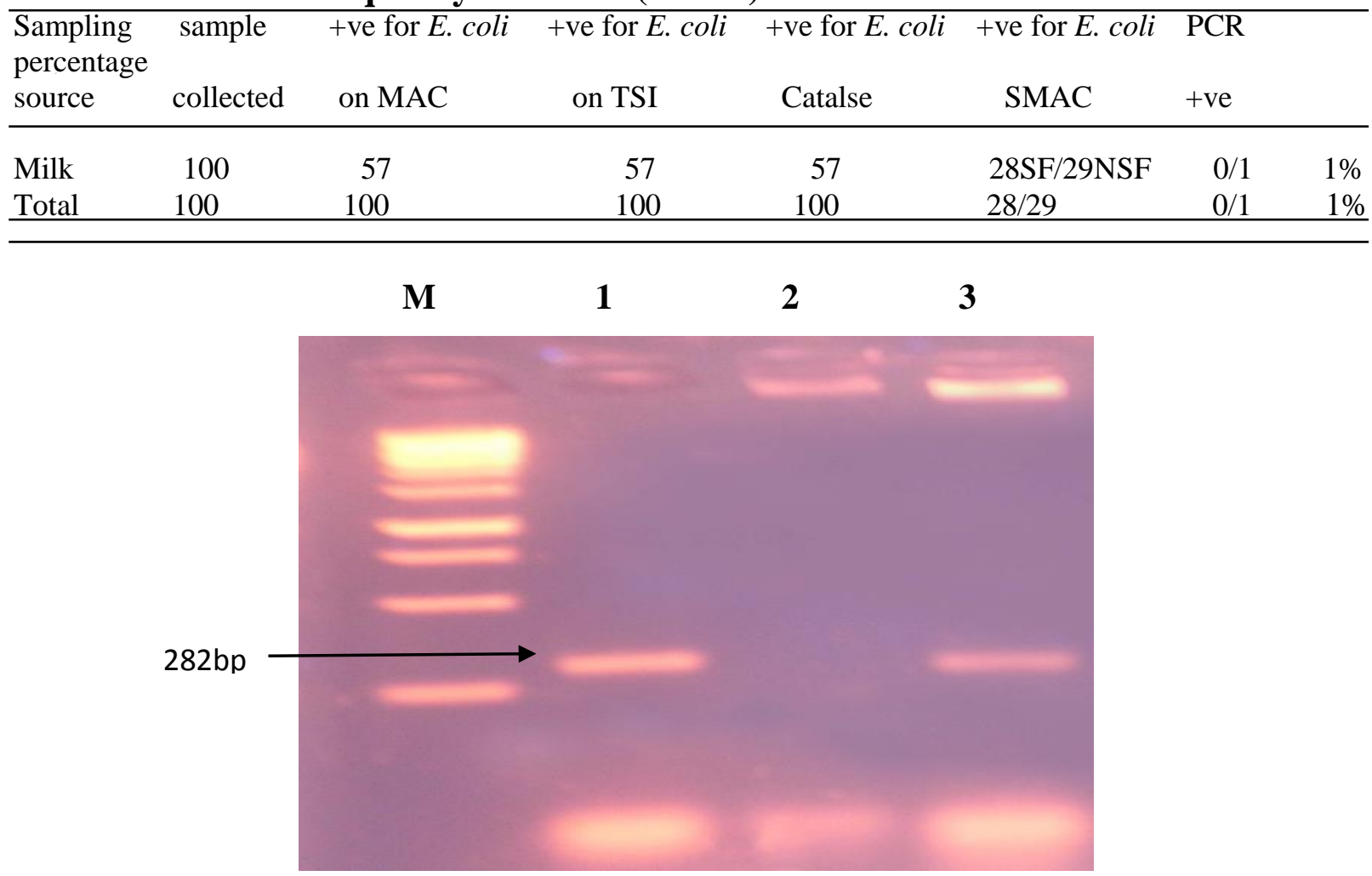

Figure 1. PCR (Milk) Lane M: Molecular weight marker of 1kb. (Thermo scientific, $0.1 \mu \mathrm{g} / \mu \mathrm{l}, 50 \mu \mathrm{g}$ ), Lane 1: Amplification product of 282 bp for $S t x 1$ gene in positive control strain EDL933, Lane 2: No amplification in negative control strain (Master MixTemplate), Lane 3: Showing amplification product of 282 bp of Stx1 gene

\section{Discussion}

Foodborne infections are caused by the consumption of contaminated food with bacteria, parasites and viruses [1]. Shiga toxin is a deadly bacterial strain usually causes foodborne illnesses and often associated with beef contamination, giving weekend state to the young, weak or elders. E. coli appears in various forms like O157, producing Shiga toxin along with the emergence of HUS [14].

The pathogenicity of E. coli $\mathrm{O} 157: \mathrm{H} 7$ is ascribed with some virulence factors such as Shiga toxins Stxl and Stx2 [15] which are encoded with Stx family and cytotoxic effects are manifested by this pathotype on endothelial cells of kidney, heart and brain [2].

From 100 samples of raw meat and milk $E$. coli was identified using plate methods incorporating MacConkey agar, Sorbitol MacConkey agar, triple sugar iron test and catalase test. Sorbitol MacConkey agar differentiated NSF and SF. These NSF colonies were further tested for PCR as these colonies were regarded as pathogenic. It is revealed from a study that from 220 samples of diarrheagenic patient only 59\% was having E. coli using MacConkey agar as initial identification. Sorbitol fermenting and non-sorbitol fermenting phenotype was identified on SMAC [16]. 
In present study the collection of samples was done between the months June to August and it was noted the positive testing was prevalent during these months. The elevation in ambient temperature is more favorable and plausible for incidence of STEC, thereby resulting in the constant source of infections. According to this information on elevation of temperature, the prevalence of STEC could be expected more, as observed, in summer season from June to August and this pathogen STEC was found in this duration to the detectable level in raw meat and milk.

In a survey of United Kingdom, it was reported that the positive testing of $E$. coli O157:H7 was only in the months between May and September. The positive testing of E. coli O157:H7 was more prevalent between June-September in United State [17].

In present study for the identification of STEC a PCR approach was employed using gene specific primers targeting virulent genes Stxl and Stx 2 and monitored with a reference strain EDL933. The specificity of PCR was validated using a reference strain and was further evaluated on 300 isolates of raw meat and milk of different geographical regions. The PCR approach was conducted for rapid and reliable identification of STEC on enrichment of samples instead of using DNA isolation procedures and plate labor intensive methods to replace the traditional tedious techniques. Out of 100 samples of milk only $(1 \%)$ number of samples were detected as positive harboring STEC genes either stxl.

Detection methods based on nucleic acid have been developed for nearly all bacterial pathogens, based on hybridization assays PCRs targeting the gene region or specific sequence of a gene. Several problems may be encountered for the direct detection of pathogens from the food samples: contamination in sensitive PCR assay, PCR inhibition by food components and detection of living as well as dead cells [18]. As described above two virulent genes were selected from the bacterium Shiga toxin producing E. coli: Stx1 and Stx2. By incorporating the PCR primers and other components, became able to develop a PCR for the detection of these genes. An important factor to evaluate DNA based test is the specificity of DNA sequence chosen for gene of interest which is going to be targeted [19]. The ability of PCR is to detect or amplify a gene or a segment of a gene directly from the sample containing various bacterial strains. One major problem in detecting the gene directly from the sample which often encountered with PCR is the reduction in sensitivity [20].

To overcome the PCR inhibition problems and to increase its sensitivity, enrichment method was employed. Enrichment method increased the number of required viable count while dead organisms reduces the probability of detection and even $2 \mu l$ of the enrichment was able to produce the PCR results which indicate the PCR sensitivity and specificity.

\section{Conclusion}

In conclusion, I developed a rapid, simple and convenient PCR-based method for the specific detection of one of the major food borne pathogens. This method rendered final results in hours rather than lengthy and equally expensive biochemical methods. Application of this method in food industries and municipal water supply departments is an additional benefit attributed to this technique.

\section{Authors' contributions}

Conceived and designed the experiments: MM Gillani \& KA Malik, Performed the experiments: A Razzaq, Analyzed the data: A Razzaq, Contributed reagents/ materials/ analysis tools: S Shamsi, Wrote the paper: A Razzaq. 


\section{References}

1. Xia X, Meng J, McDermott PF, Ayers S, Blickenstaff K, Tran TT, Abbott J, Zheng J \& Zhao S (2010). Presence and characterization of shiga toxinproducing Escherichia coli and other potentially diarrheagenic E. coli strains in retail meats. Appl Environ Microbiol 76(6): 1709-171.

2. Muller D, Greune L, Heusipp G, Karch H, Fruth A, Tschape H \& Schmidt MA (2007). Identification of Unconventional Intestinal Pathogenic Escherichia coli Expressing Intermediate Virulence Factor Profiles with a Novel Single Step Multiplex PCR. Appl Environ Microbiol

3. Perna NT, Plunkett G, Burland V, Mau B, Glancer JD, Rose DJ, Mayhew GF, Evan PS, Gregor J, Kirkpatrick HA, Posfai G, Hackett J, Klink S, Boutin A, Shao Y, Miller L, Grotbeck EJ, Davis NW, Lim A, Dimalanta ET, Potamousis KD, Apodaca J, Anantharaman TS, Lin J, Yn G, Schwartz DC, Welch RA \& Blattner FR (2001). Genome sequence of enterohemorrhagic E. coli O157: H7. Nat 409: 529533

4. World Health Organization (2007). First formal meeting of foodborne diseases. Burden epidemiology reference group (FERG), Genewa, WHO

5. Schmidt H, Scheef J, Huppertz HI, Frosch M \& Karch H (1999). Escherichia coli O157:H7 and O157:H2 strains that do not produce Shiga toxin: phenotypic and genetic characterization of isolates associated with diarrhea and hemolyticuremic syndrome. J Clin Microbiol 37: 3491-3496.

6. Josefa MR, Phyllis H, Sparling CC, Patricia MG \& David LS (2005). Emerging Infectious Diseases. www.cdc.gov/eid.11 (4).

7. Halabi M, Orth D, Grif K, Wiesholzerpittl M, Kainz M, Schoberl J, Dierich MP, Allerberger F \& Wurzner R (2008).
Prevalence of Shiga toxin-intimin and haemolysin genes in $\mathrm{E}$, coli isolates from drinking water supplies in a rural area of Austria. Intl J Hyg Environ Health 211: 454-457.

8. Morgan D, Gunneberg C, Gunnell D, Healing TD, Lamerton S, Soltanpoor N, Lewis DA \& White DG (1994). An outbreak of Campylobacter infection associated with the consumption of unpasteurized milk at a large festival in England. Europ J Epidemiol 10: 581-585.

9. Bender JB, Hedberg CW, Boxrud DJ, Besser JM, Wicklund JH, Smith KE \& Osterholm MT (2001). Use of molecular subtyping in surveillance for Salmonella enterica serotype typhimurium. $N$ Engl J Med 344: 189-195.

10. Tom S, Edrington TR, Sam EI, Mike JE, Mike LL, Robin CA \& David JN (2006). Seasonal Shedding of Escherichia coli O157:H7 in Ruminants: A New Hypothesis. Foodborne Pathog and Dis 3(4): 413-421.

11. Griffin PM \& Tauxe RV (1991). The epidemiology of infections caused by Escherichia coli O157:H7, other enterohemorrhagic $E$. coli, and the associated hemolytic uremic syndrome. Epidemiol Rev 13: 60-98.

12. Ludwig $\mathrm{K}$, Ruder $\mathrm{H}$, Bitzan $\mathrm{M}$, Zimmermann S \& Karch H (1997). Outbreak of $E$ coli infection in large family. Eur J clin Microbiol infect Dis 16: 238-241.

13. CDC (2016). Multistate Outbreaks of Shiga toxin-producing Escherichia coli $\mathrm{O} 26$ Infections Linked to Chipotle Mexican Grill Restaurants (Final Update)

14. Thompson DE (1994). The role of mycobacteria in Crohn's disease. J. Med. Microbiol. 41: 74-94.

15. Chen S, Xu R, Yee A, Wu KY, Wang CN, Read S \& De Grandis SA (1998). An automated fluorescent PCR method for detection of Shiga toxin-producing 
Escherichia coli in foods. Appl Environ Microbiol 64: 4206-4210.

16. Mohsin M., Ali A, Sarwar A, Bashir Y, Tariq S, Afzal A, Ifthikhar A \& Saeed MA (2010). Effect of ampicillin, gentamicin, and cefotaxime on the release of Shiga toxins from Shiga toxin producing Escherichia coli isolated during a diarrhea episode in Faisalabad, Pakistan. Foodborne Pathog Dis 7: 8590.

17. Chapman P.A., Malo ATC \& Ellin M (2001). Escherichia coli O157 in cattle and sheep at slaughter, on beef and lamb carcasses and in raw beef and lamb products in South Yorkshire, UK. Int $J$ Food Microbiol 64: 139-150.
18. Heyndrickx MN, Rijpens \& Herman L (2001). Molecular detection and typing of foodborne bacterial pathogens. Appl Microbiol 11: 193-238.

19. Winters DK, O'Leary AE \& Slavik MF (1998). Polymerase chain reaction for rapid detection of Campylobacter jejuni in artificially contaminated foods. Lett Appl Microbiol 7: 163-167.

20. Mousavi SL, Rasooli I, Nazarian S \& Jafar A (2009). Simultaneous detection of Escherichia coli O157:H7, toxigenic Vibrio cholerae, and Salmonella typhimurium by multiplex PCR. Iran J of Clin Infect Dis 4(2): 97-103. 